\title{
A New Approach for Interpreting Long-Run Returns, Applied to IPO and SEO Stocks
}

\author{
Jan Bo Jakobsen \\ Nordea Investment Management Strandgade 3 DK-1401 Copenhagen K, Denmark \\ E-mail: jan.jakobsen@nordea.com \\ and \\ Torben Voetmann ${ }^{*}$ \\ Department of Finance, The Wharton School and Cornerstone Research 3620 \\ Locust Walk, SHDH 2344 Philadelphia, PA 19104-6367 \\ E-mail: voetmann@wharton.upenn.edu
}

\begin{abstract}
In this paper, we introduce a new approach for interpreting long-run returns; which we then test on IPOs and SEOs in Denmark. We demonstrate that by decomposing the mean and volatility components of the expected crosssectional buy-and-hold returns, we can improve the interpretation of long-run returns. Using a traditional method, we found that after five years the buyand-hold returns of IPO and SEO stocks underperformed the market by 27.3 percent and 21.4 percent, respectively. By applying the new approach we found that after five years the same stocks underperformed by 43.7 percent and 38.1 percent. Although underperformance has long been documented in the empirical literature, we found that the underperformance is larger than previously documented. (c) 2005 Peking University Press
\end{abstract}

Key Words: Wealth relatives; Buy-and-hold returns; Right skewed distributions. JEL Classification Numbers: G14, G32.

* Corresponding author. We would like to thank participants and discussants at the Financial Management Association International Annual European Meeting 2000, the European Financial Management Association Annual Meeting 2000, and the Financial Management Association Annual Meeting 2001. We are also grateful to Tracey E. Hall for her editorial assistance. Any comments are gratefully appreciated. The usual disclaimer applies.

337

1529-7373/2005

Copyright (c) 2005 by Peking University Press All rights of reproduction in any form reserved. 


\section{INTRODUCTION}

Many studies have documented that the distribution of right-skewed abnormal returns is significantly different from zero (see among others Barber and Lyon (1997), Cowan and Sergeant (1997), Mitchell and Stafford (1999), Lyon, Barber and Tsai (1999), and Brav (2000)). However, ways to correctly test abnormal returns with the existence of right skewness have not been well documented. This paper is an extension of these earlier studies; we describe a new test procedure that takes advantage of the skewness properties of the lognormal distribution, and the cross-sectional distribution of long- run returns. We then apply our test procedure on a sample of initial public offerings (IPOs) and seasoned equity offerings (SEOs) from Denmark: all those between 1983 and 1998. We also use this technique to compare the performance of IPO stocks in a hot and a cold issue pe riod.

A key to our technique is the use of wealth relatives (WR) to measure long-run returns as recommended by Ritter (1991), Loughran and Ritter (1995), and Spiess and Affleck-Graves (1995). Ritter described a puzzle to which we respond: why do long- run returns of equity offerings persistently underperform? As key to the puzzle we measure long-run returns using WRs. Decomposing the relatives gives us an answer: we still see underperformance but we can explain it better.

Applying our approach on a sample of Danish IPO and SEO stocks we found the underperformance is larger than previously documented when we consider the upward bias caused by the volatility component in the rightskewed wealth relatives. Using our new approach, we found that IPO and SEO stocks underperform relative to the market by 43.7 percent and 38.1 percent after five years, respectively. We also tested the volatility-adjusted performance on a sample of both hot and cold period equity issues. We found that the under performance after one year is similar for hot and cold issues; after five years hot issues underperform significantly by 50.0 percent and cold issues under perform insignificantly by 22.6 percent. This indicates that it is better in the long run to invest in firms going public in a cold issue period than in a hot issue period.

The remainder of this paper is organized as follows. Section 2 describes how prior studies measure long-run returns. Section 3 presents our methodology. Section 4 introduces the data. The results are discussed in section 5 , and section 6 concludes the paper.

\section{MEASURING LONG-RUN RETURNS}

\subsection{Long-Run Returns of IPO and SEO Stocks}

Although Ritter (1991) and Spiess and Affleck-Graves (1995) are puzzled by the persistence of negative long-run returns after equity offerings, 
we suggest that the volatility is important in explaining the observed persistence of long-run returns. Ritter (1991) examines 1,526 IPO stocks and finds a negative 15.08 percent average cumulative matching firm-adjusted return after 36 months. Comparing returns from firms of similar size and industry, the average IPO stock's cumulative abnormal returns are negative 26 percent. Ritter (1991) argues that the result is consistent with investors being overoptimistic about potential growth firms. Loughran and Ritter (1995) exa mine the five-year long-run return for 4,753 IPO stocks and 3,702 SEO stocks in the United States during 1970-1990. The average long run return of IPO stocks, adjusted for size and industry, under performed by 20 percent after three years; for SEO stocks, long-run returns under performed by 22 percent. Both studies calculated buy-and-hold returns and argued that the results deviate from those predicted by the long-run eff icient market theory. Similarly, Spiess and Affleck-Graves (1995) examined 1,246 seasoned equity offerings during the period 1975-1989 and found a negative abnormal return of 22 percent when compared to matching firms over a five-year post-event period. The results are persistent when adjusting for trading system, offer size, and the issuing firm's age and book-tomarket value. This is not only a US phenomenon. Many studies document underperformance in other countries over various time periods. ${ }^{1}$ Despite all these studies, at present, no existing theory can convincingly explain long run under performance in IPOs and SEOs.

The most promising explanation is that investors overreact and are overly optimistic about the information revealed through equity offerings. Spiess and Affleck-Graves (1995) examine the abilities of managers to take advantage and exploit overvaluation. They argue that managers have an opportunity to exploit overvaluations in SEO stocks; they found that managers issue equity when the stock is overvalued because they are able to take advantage of firm-specific information. Comparing the under performance of IPO stocks and SEO stocks supports their findings that managers can

\footnotetext{
${ }^{1}$ Loughran, Ritter, and Rydqvist (1994) compare IPO stocks for 24 countries that de monstrate similar patterns, although some find positive long-run returns (see Loderer and Zimmermann (1988), B.hren, Eckbo and Michalsen (1997), Bigelli (1997), and Dubois and Jeanneret (1998)). For comprehensive sur veys see Smith (1986), Eckbo and Masulis (1995), Ibbotson and Ritter (1995) for IPO stocks, and Eckbo and Masulis (1995) for SEO stocks. Other fin dings from non-US studies showing positive returns are Hietala and L.yttyniemi (1991) for Finland, Dhatt, Kim and Mukherji (1996) for Korea, Tsangarakis (1996) for Greece, and Kang and Stulz (1996) for Japan. Levis (1993) reports a three-year underperformance in IPO stocks from the United Kingdom; such stocks experience an average 30 percent loss of value compared to the market. Lee, Taylor and Walters (1996) also found that the market-adjusted cumulative average returns from Australian IPO stocks under perform over a three-year period. Corresponding results are found in Aggarwal et al. (1993) for Brazil and Chile, Keloharjo (1993) for Finland, Kunz and Aggarwal (1994) for Switzerland, and Page and Reyneke (1997) for South Africa.
} 
also exploit overvaluation opportunities in SEO stocks. That is, it is not only the vast information asymmetry in IPO stocks that allows managers to exploit overvaluation. ${ }^{2}$ Empirically, our findings complement these results; however, the task of future research is still to develop a consistent theory.

We partitioned the IPOs and SEOs into a hot (cold) issue period, and investigated the IPO stocks for the hot issue period 1983-1986. High initial returns and high volumes characterize hot issue periods, i.e. an IPO stock tends to rise above the offering price gaining a higher than average premium in the aftermarket (see Ibbotson and Jaffe (1975) and Loughran, Ritter and Rydqvist (1994)). Loughran and Ritter (1995) argue that in periods with few IPOs the underperformance is modest, which is confirmed in our cold issue period. Hot issue periods experience a more severe long-run underperformance than cold issue periods. Loughran, et al. also document the tendency toward high initial returns and volumes after a period of high stock market performance.

\section{2. $\quad$ Testing long-run returns}

Previous studies relied on conventional statistics that are not necessarily valid, given the distribution properties of the long-run returns. As Fama (1998) has argued, none of these studies actually tested for whether securities are under performing or over performing on average. ${ }^{3}$ Fama argues that the market efficiency hypothesis is still valid because the anomalies disappear with changes in the estimation model of the expected returns. That is, the estimation methodology itself may cause long-run anomalies. Also, inferences about long-run returns are problematic due to unavoidable "bad-model" problems and sample-specific patterns in average returns. Our approach relies on the distribution properties of Ritter's WR.

Previous studies have identified other issues. Conrad and Kaul (1993) showed that a potential bias (upward or dow nward) is induced by cumulative abnormal returns over the long run. Barber and Lyon (1997) and

\footnotetext{
${ }^{2}$ Two alternative and promising explanations are the theory of investor sentiment. Barberis, Shleifer and Vishny (1998) and Daniel, Hirshleifer and Subrahmanyam (1998) explain long-run performance with behavioral model of investor sentiment. The behavior models provide an alternative explanation of investors' behavior but not a better explanation of the long-run anomalies.

${ }^{3}$ For studies of under (over) performance, see Agrawal, Jaffe and Mandelker (1992) for mergers and acquisitions, Ikenberry, Lakonishok and Vermaelen (1995) for share repurchases, Michaeley, Thaler and Womach (1995) for dividend initiations and omissions, Speiss and Affleck-Graves (1995) for seasoned equity offerings, Loughran and Vijh (1997) for corporate acquisitions, and Ritter (1991), Loughran and Ritter (1995 ) for initial public offerings. The results from various kinds of event studies show that over reaction in the marketplace is as common as under reactions; therefore, Fama (1998) argues that the post-event reversals are as frequent as the post-event continuations of pre-event returns.
} 
Kothari and Warner (1997) find severe problems related to the fact that abnormal returns are non-normally distributed as they become right skewed after certain periods of time. Symmetric and independently distributed periodic returns induce right skewness and autocorrelation in accumulated returns. This right skewness is caused by the accumulation method used to test buy-and-hold returns. Barber and Lyon (1997) address problems concerning mis-specifications that arise from re-balancing, new listing, and right skewness biases. These problems affect the conventional test methods: many empirical results make inferences based on incorrect test statistics. ${ }^{4}$

Despite all these studies no one has addressed test statistics, an issue we now address. Barber and Lyon (1997) argue that the mis-specification causes the inference based on long-run returns to be incorrect. They argue that it is possible to achieve well- specified test statistics when the usual BHAR is corrected by matc hing sample firms with control firms of similar size and book-to-market ratios. ${ }^{5}$ Kothari and Warner (1997) suggest that a parametric shift in the event window influences the tests of accumulated returns, e.g. the interference must include the possible increase in variability of abnormal returns. Lyon, Barber and Tsai (1999) suggest that correcting the usual t-test statistic can capture the skewness of the distribution of the buy-and-hold abnormal returns.

\section{METHODOLOGY}

In this paper, we apply an extension of Ritter's WR. We calculated the cross- sectional averages of the buy-and-hold returns using three different methods: two traditional methods and our new method. Method one, the most commonly used, is a simple cross-sectional arithmetic average calculation that does not adjust for right-skewed long-run returns. Method two is a calculation of the average cross-sectional return as the expected value of log-normally distributed buy-and-hold returns. A problem with the first and second methods is that the expected value of such returns cannot be tested directly because the volatility causes an upward bias. Method three responds to this problem by decomposing the expected cross-

\footnotetext{
${ }^{4}$ See Conral and Kaul (1993), Barber and Lyon (1997), Canina, Michaely, Thaler, and Womack (1997), Kothari and Warner (1997), Cowan and Sergeant (1997), Lyon, Barber and Tsai (1999) for warnings about the buy-and-hold return methodology used to estimate abnormal returns.

${ }^{5}$ Fama (1998) argues that corrections of expected returns using a matching approach based on size and $\mathrm{BE} / \mathrm{ME}$ does not limit bad-model problems. Abnormal returns vary whether matching is based on size or size and BE/ME. Fama (1998) argues that this matching approach does not cap ture the cross sectional variation in expected returns. Therefore, a matching approach for expected returns is not a panacea for bad-model problems. In particular in long-run event studies because the standard error in abnormal return increases with the number of months.
} 
sectional mean buy-and-hold returns into transformed mean components and volatility components. By decomposing the average cross-sectional mean buy-and-hold return into levels, we can more accurately interpret the under performance or over performance. In this section, we describe the WR, decomposition, and testing.

\subsection{Wealth Relatives}

The buy-and-hold return is calculated for each security, $i$, from the announcement day to some future date $T$. An initial amount $W_{i, 0}$ is invested in each security, $i$, with a stochastic periodic (monthly) return, $r_{i, t}$, that is realized at the end of period $t$. The invested amount accumulates after $T$ periods to $W_{i, T}$ :

$$
W_{i, T}=W_{i, 0} \cdot \prod_{t=1}^{T}\left(1+r_{i, t}\right)
$$

Without loss of generality, the initial amount $W_{i, 0}$ can be set equal to one and the buy-and-hold return is equal to $\prod_{t=1}^{T}\left(1+r_{i, t}\right)-1$. Typically, the distribution of buy-and-hold returns is right-skewed, even if the distribution of periodic returns is symmetrical. We use buy-and-hold returns beca use they capture the compounding effect of monthly returns. Also, we calculate the ratio between two portfolios instead of calculating the difference between the buy-and-hold returns of two portfolios. ${ }^{6}$ The wealth relative between two accumulated values is the ratio between the wealth $W_{i, T}$ that results from investing in a security and the wealth $W_{m, T}$ from investing in the market index after $T$ periods. This accumulated wealth relative follows the spirit of Ritter (1991) and Loughran and Ritter (1995). ${ }^{7}$ The wealth relative can be measured as either the market-to-security (WRMS) ratio, $W_{m-i, T}=\left(W_{m, T} / W_{i, T}\right)$, or the security-to-market (WRSM) ratio,

\footnotetext{
${ }^{6}$ Barber and Lyon (1997) and Kothari and Warner (1997) investigate the difference between the buy- and-hold returns of two portfolios.

${ }^{7}$ Ritter (1991) and Loughran and Ritter (1995) use the wealth relatives differently by taking the average in the numerator and the denominator. Our approach is more applicable because the wealth rel ative is lognormal distributed. An alternative to the wealth relative is the transformed buy -and-hold abnormal return (T-BHAR) where we compounded abnormal returns over time, which can also be accepted lognormal distributed (see appendix A). The T-BHAR states that an investor holds a long position in the market index and a short position in the equity offering in which the proceed are realized monthly and reinvested assuming no transaction costs.
} 
$W_{i-m, T}=\left(W_{i, T} / W_{m, T}\right){ }^{8}$ The accumulated $W R_{S M}$ after $T$ months is:

$$
W_{i-m, T} \equiv W_{i-m, 0} \cdot \frac{\prod_{t=1}^{T}\left(1+r_{i, t}\right)}{\prod_{t=1}^{T}\left(1+r_{m, t}\right)}=W_{i-m, 0} \cdot \prod_{t=1}^{T} \frac{\left(1+r_{i, t}\right)}{\left(1+r_{m, t}\right)}
$$

where $i=\{1, \ldots, N\}$ and $T=\{1, \ldots, 60\}$. Taking the logarithm of the wealth relative and assuming that $\left(W_{i, 0} / W_{m, 0}\right)=1$ the expression becomes:

$$
\log \left(W_{i-m, T}\right)=\sum_{t=1}^{T} \log \left(1+r_{i, t}\right)-\sum_{t=1}^{T} \log \left(1+r_{m, t}\right)
$$

If the logarithms of the periodic (monthly) returns are normally distributed the buy-and-hold returns of the securities, the benchmarks, and the wealth relatives will be log-normally distributed. Even if the periodic returns of the securities or the benchmark are not normally distributed it may still be the case that when we subtra ct the periodic (monthly) returns of the security, the benchmark turns out to be normally distributed. In other words, in (3) the left-hand side may be normally distributed even if the individual terms on the right-hand side are not normally distributed. The transformation of wealth relatives from logarithmic values to level values using exact expressions in discrete time is:

$$
W_{i-m, T}=e^{\sum_{t=1}^{T}\left(\log \left(1+r_{i, t}\right)-\log \left(1+r_{m, t}\right)\right)}
$$

If the wealth relative is log-normally distributed, an inherent relationship exists between the geometric Brownian motion and the development in the wealth relatives. The geometric Brownian motion provides an explicit structure for the wealth relative that describes the development of the buyand-hold returns over time. The common interpretation of the geometric Brownian motion calls for a constant drift and volatility parameter over time. Using these parameters, the cross-sectional buy-and-hold returns of the $W R_{S M}$ can be expressed with the geometric Brownian motion as:

$$
W_{i-m, T}=e^{\left(\mu_{T}-\frac{1}{2} \sigma_{T}^{2}\right) \cdot T+\sigma_{T} \cdot Z_{T}}
$$

where $\mu_{T}=\alpha_{T}+\frac{1}{2} \sigma_{T}^{2}$. The parameters $\alpha_{T}, \mu_{T}$, and $\sigma_{T}$ are constants and $\left\{Z_{t}\right\}_{t \geq 0}$ is a Wiener process with $d Z_{t} \sim N(0, d t)$. Expression (5) allows the constants $\alpha_{T}$ and $\sigma_{T}$ to vary depending on the time horizon $T$. This flexibility is based on the assumption that the cross-sectional means at any given time horizon $T$ can be treated as independent observations.

\footnotetext{
${ }^{8}$ It is necessary to investigate both types of wealth relative ratios because we want to capture the variation between the components of the wealth relative and we want to demonstrate that it is independent of the used wealth relative ratio.
} 


\subsection{Decomposing the Wealth Relative}

Given that the $W R_{S M}$ follows a lognormal distribution, its logarithm is normally distributed using transformed mean $\alpha_{T} \cdot T$ and standard deviation $\sigma_{T} \sqrt{T}$. The expected buy-and-hold return of the wealth relative in levels is:

$$
E\left(W_{T}\right)=e^{\mu_{T} \cdot T}=e^{\alpha_{T} \cdot T+\frac{1}{2} \sigma_{T}^{2} \cdot T}=\underbrace{e^{\alpha_{T} \cdot T}}_{\begin{array}{c}
\text { Transformed } \\
\text { meancomponent }
\end{array}} \cdot \underbrace{e^{\frac{1}{2} \sigma_{T}^{2} \cdot T}}_{\begin{array}{c}
\text { Volatility } \\
\text { component }
\end{array}}
$$

From expression (6) and for any given time period $T$, the expected value of the wealth relative depends on the mean and the volatility component. If there is no noise, meaning that the volatility component is zero, the wealth relative is purely derived from the drift and the time horizon in expression (6). The volatility effect is always positive and identical irrespective of which measure is used: $W R_{M S}$ or $W R_{S M}$. Although this may appear inconsistent, there is nothing peculiar about the result because the volatility component captures the variation between the buy-and-hold returns of the security and those of the market that together compose the wealth relative ratio. There fore, we do not draw inferences on each of the buy-and-hold returns; we only make inferences about the wealth relative using the decomposition in expression (6). We decompose the cross-sectional mean, $e^{\mu_{T} \cdot T}$, into its transformed mean component, $e^{\alpha_{T} \cdot T}$, and its volatility component, $e^{\frac{1}{2} \sigma_{T}^{2} \cdot T}$ to better understand the impact of volatility. Not only does the geometric Brownian motion representation explicitly depict the transformed mean component and the volatility component, it also captures the feature that the periodic (monthly) returns may be symmetric and independently distributed while the buy-and-hold returns of the wealth relatives exhibit right skewness.

\subsection{Tests of the Transformed Mean and Volatility Components}

The wealth relative that is described in expression (5) is log-normally distributed. Thus, when the logarithm is taken it becomes normally distributed:

$$
\log \left(W_{i-m, T}\right) \sim\left(\alpha_{T} \cdot T, \sigma_{T}^{2} \cdot T\right)
$$

Given that the logarithm of the wealth relative is normally distributed, we can estimate the parameters for the transformed mean and variance:

$$
\begin{aligned}
\hat{\alpha}_{T} & =\frac{1}{T \cdot N} \sum_{i=1}^{n} \log \left(W_{i-m, T}\right) \\
\hat{\alpha}_{T}^{2} & =\frac{1}{T \cdot(N-1)} \sum_{i=1}^{N}\left(\log \left(W_{i-m, T}\right)-\hat{\alpha}_{T} \cdot T\right)^{2}
\end{aligned}
$$


The parameter estimates $\left(\hat{\alpha}_{T}\right.$ and $\left.\hat{\sigma}_{T}^{2}\right)$ are marginal parameter estimates at any point in time. They are based only on the expected cross-sectional wealth relative at time $T$. If we accept the logarithms of the cross-sectional wealth relative as being normally distributed, the estimated mean component is $\hat{\alpha}_{T} \cdot T$ and the estimated standard deviation of $\log \left(W_{i-m, T}\right)$ is $\hat{\sigma}_{T} \cdot \sqrt{T}$. The marginal estimates $\hat{\alpha}_{T} \cdot T$ and $\hat{\sigma}_{T} \cdot \sqrt{T}$ can be tested against alternatives using the cross-sectional wealth relatives at time $T$. For example, two independent hypotheses could be the following:

$$
H_{0}: \alpha_{T} \cdot T=0 \text {, versus } H_{1}: \alpha_{T} \cdot T \neq 0
$$

or

$H_{0}: \sigma_{T} \cdot \sqrt{T}=\lambda$, versus $H_{1}: \sigma_{T} \cdot T \neq \lambda$

where $\lambda$ can be any positive value. The marginal confidence interval of the marginal estimate $\alpha_{T} \cdot T$ is $t$-distributed at time $T$ and the marginal confidence interval of the marginal estimate $\hat{\sigma}_{T} \cdot \sqrt{T}$ is $\chi^{2}$-distributed at time $T$, both with $N-1$ degrees of freedom. The marginal estimates can be transformed back to levels through the exponential function and the resulting expected buy-and-hold returns can be compared to the wealth relative. This ensures that the transformed mean components $e^{\hat{\alpha}_{T} \cdot T}$ and the volatility components $e^{\frac{1}{2} \hat{\sigma}_{T}^{2} \cdot T}$ can be compared to the expected buyand-hold returns, $e^{\mu_{T} \cdot T}$.

To summarize, the method we apply in this paper investigates the crosssectional buy- and-hold returns of wealth relatives. It identifies log-normally distributed long-run returns and decomposes the expected cross-sectional buy-and-hold returns into transformed mean components and volatility components. Adjusting for the volatility component, the transformed mean component provides a testable and correct estimate of long-run returns. ${ }^{9}$

\section{DATA}

We constructed a sample by gathering information on IPOs and SEOs during the period 1983-1998. We used datasets from Account Data that contain information on equity offerings by firms that are listed on the Copenhagen Stock Exchange; this data identifies the type of equity offering and its characteristics. ${ }^{10}$

For the equity offering to be included in the sample it had to meet three criteria: 1) the issue had to be a primary offering, i.e. we excluded offerings that included preferred and secondary shares; 2) joint offerings were excluded; and 3) the offering firm had to be listed on Account Data's secu-

\footnotetext{
${ }^{9}$ Appendix B describes the relationship between the geometric Brownian motion and the lognormal distribution.

${ }^{10}$ Account Data is a database that contains information about all firms that are listed on the Copenhagen Stock Exchange. It contains annual reports and market information about each firm/security.
} 
rity price information at the time of the issue. In addition, we evaluated the pricing information to identify and exclude any equity offerings in which observations were missing during the six months following the equity issue. Further, if the offering firm was de -listed less than five years after the equity offering, we truncated the buy-and-hold returns of the firm and the matching index at the same time. Applying these criteria we developed a sample of 142 IPO stocks and 413 SEO stocks. Table 1 shows the distribution of the total sample of IPO stocks and the partition of SEO stocks by years.

Table 1 shows an aggregate issue amount for IPO stocks of 6,604 million DKK and 17,908 million DKK for SEO stocks that yields proceeds of 23,849 million DKK and 46,717 million DKK, respectively. ${ }^{11}$ We found a large number of equity offerings in 1984, 1985, and 1986. Table 1 also shows that the number of IPOs is, on average, about the same as the number of SEOs in those years, but that later on there were four to five times as many SEOs as IPOs. The number of SEO stocks is more evenly distributed than the number of IPOs over the years 1983 to 1998, varying between 43 offerings in 1986 and 15 offerings in 1987. Of the 413 SEOs represented in the sample 242 firms made equity offerings more than once during the sample period; ${ }^{12}$ the other 224 firms in the sample did not. Loughran and Ritter (1995) argue that the under performance in periods with few IPOs is modest; therefore, we partitioned the sample into sub periods which we call hot-issue and cold-issue periods to determine whether or not this is evident in our sample.

To measure the long-run return of an equity issue, we calculated the buyand-hold return from the first day of trading over a period of 60 months. We considered two benchmark returns of the post-offering period: marketadjusted returns and market-model returns. To estimate the market-model returns, we used the post-offering period as the estimation window. ${ }^{13}$ Our reasoning is that before an SEO the stock price typically increases, but then remains stable post-issue (Lee et al., 1996).

\section{RESULTS}

\subsection{Long-Run Security Performance}

Table 2 shows the average buy-and-hold returns of IPO stocks (panel A) and SEO stocks (panel B) using cross -sectional averages, wealth relatives,

\footnotetext{
${ }^{11}$ During this time period, one $\$$ approximately equaled eight DKK.

12107 firms made two, 61 made three issues; and 34 made four issues, 19 made five issues, 11 made six issues, 5 made seven issues, 3 made eight issues, 2 made nine issues.

${ }^{13}$ Estimating parameters prior to SEO stocks, as an alternative, provides results (not reported) that are similar to those of the using post parameters.
} 
TABLE 1.

Distribution of Equity Offerings on the Copenhagen Stock Exchange We construct our sample by gathering information of IPOs and SEOs during the period 1983-1998. The data source is Account Data for identifying security offerings and offerings characteristics. The total sample consists of all equity offerings on the Copenhagen Stock Exchange. For an equity offering to be included in the sample it must meet the following three criteria: 1 ) the issue must be a primary offering, i.e. offerings that include secondary shares are excluded; 2) joint offerings are excluded; and 3) the offering firm must be listed on the Account Data's database of security price information at the time of the issue. In addition, we evaluate the pricing information to identify and exclude any equity offerings in which missing observations exist during the six months following the offering. Offering is the nominal equity issue and proceed is the market capitalization of the issue.

\begin{tabular}{|c|c|c|c|c|c|c|}
\hline \multirow[b]{2}{*}{ Year } & \multicolumn{3}{|c|}{ IPOs } & \multicolumn{3}{|c|}{ SEOs } \\
\hline & Number & Offering $^{a}$ & Proceed $^{a}$ & Number & Offering $^{a}$ & Proceed $^{a}$ \\
\hline 1983 & 7 & 63 & 220 & 24 & 533 & 779 \\
\hline 1984 & 23 & 298 & 786 & 27 & 893 & 1,731 \\
\hline 1985 & 12 & 547 & 3,882 & 25 & 955 & 1,603 \\
\hline 1986 & 23 & 381 & 845 & 43 & 1,389 & 3,453 \\
\hline 1987 & 4 & 21 & 59 & 15 & 619 & 1,353 \\
\hline 1988 & 3 & 252 & 325 & 24 & 364 & 1,283 \\
\hline 1989 & 9 & 1,160 & 1,276 & 32 & 1,280 & 3,727 \\
\hline 1990 & 12 & 731 & 1,582 & 24 & 1,123 & 3,579 \\
\hline 1991 & 8 & 682 & 1,646 & 31 & 2,674 & 10,258 \\
\hline 1992 & 4 & 257 & 292 & 27 & 2,639 & 4,569 \\
\hline 1993 & 4 & 503 & 1,732 & 16 & 159 & 287 \\
\hline 1994 & 6 & 1,152 & 3,007 & 26 & 2,517 & 6,112 \\
\hline 1995 & 10 & 207 & 2,344 & 27 & 613 & 2,164 \\
\hline 1996 & 6 & 273 & 4,778 & 23 & 1,122 & 2,167 \\
\hline 1997 & 4 & 17 & 234 & 33 & 753 & 2,808 \\
\hline 1998 & 7 & 59 & 840 & 16 & 276 & 846 \\
\hline Total & 142 & 6,604 & 23,849 & 413 & 17,908 & 46,717 \\
\hline
\end{tabular}

${ }^{a}$ Amount issued and proceeds in millions DKK.

and transformed buy-and-hold returns. ${ }^{14}$ The average cross-sectional buyand-hold returns show that the IPOs and SEOs constantly under perform

\footnotetext{
${ }^{14}$ Ritter (1991) argues that the use of equally weighted monthly returns imply an increasing investment in poorly performing firms is avoided using independent monthly rebalancing. However, the long-run returns using this technique may be downw ards biased. In addition, Lee et al. (1996) argue that this rebalancing assumption is in
} 
the market when the benchmark is the market-adjusted return. Spiess and Affleck-Graves (1995) documented similar results using average cumulative returns that are adjusted for size, industry and size, and book-to-market and size.

The results in Table 2 need to be interpreted with caution because the distribution properties of the buy-and-hold returns are unknown. The cross-sectional standard deviations are not sufficient statistics if the buyand-hold returns are not symmetrically distributed around the averages. Panel A shows that the average cross-sectional buy-and-hold return after 60-month is 2.5 percent for IPO stocks and 15.8 percent for the market index. After the first 12 months the IPO stocks outperform the market by 7.75 percent $\left(\frac{1.057}{0.981}-1\right)$; after 60 months this rises to 11.5 percent $\left(\frac{1.025}{1.158}-1\right)$. This under performance is of the same magnitude as the findings in Spiess and Affleck-Graves (1995) and Loughran and Ritter (1995) using data from the United States. The 60 month buy-and-hold return from wealth relatives defined as the IPO stocks relative to the market index $(\mathrm{S} / \mathrm{M})$ is negative 27.3 percent. However, for the wealth relative of the market against the IPO stocks (M/S), the average buy-and-hold return is 152.6 percent. Panel $\mathrm{B}$ shows that the average buy-and-hold return after 60 months is 6.1 percent for SEO stocks and 40.4 percent for the market index. The SEO stocks constantly under perform the market, e.g. by 5.4 percent after the first 12 months and by 22.3 percent after 60 -month. The 60 -month buyand-hold return from the wealth relative defined as the SEO stocks against the market $(\mathrm{S} / \mathrm{M})$ return is negative 21.4 percent. However, for the wealth relative of the market against the SEO stocks $(\mathrm{M} / \mathrm{S})$ the average buy-andhold return is 128.4 percent. The results in Table 2 show that the expected buy-and-hold return depends on the method used to calculate the long-run returns. Overall, the results show that the buy-and-hold returns of the IPO and SEO stocks vary more than those of the market.

\subsection{Results with Lognormal Transformation}

The differences in the average buy-and-hold return for the market-tosecurity wealth relative and the security-to-market wealth relative are due to the volatility component. Figure 1, panel A and panel $\mathrm{C}$ show the development in the expected buy-and-hold, return of wealth relatives shown as the normalized measure: $e^{\mu_{J, T} \cdot T}-1$. (Table 3 summaries the results for selected years.) Figure 1, panel B and panel D, shows the decomposition of the expected buy-and-hold return into the normalized transformed , mean component, $e^{\alpha_{J, T} \cdot T}-1$ and the normalized volatility component, $e^{\frac{1}{2} \sigma_{J}^{2} \cdot T}-1$, where $J=\{i-m, m-i\}, i=\{$ IPOstocks, SEOstocks $\}$ and $T=\{1, \ldots, 60\}$.

conflict with the problem concerning calendar time intervals, i.e. it is not possible to create a feasible investment strategy. 


\section{TABLE 2.}

Long-Run Returns for IPOs and SEOs

The time horizon is shown in the first column. The buy-and-hold returns are calculated assuming that an investor invests in an equally weighted portfolio of firms at the day of the equity offering. The Twealth relatives are used to calculate buy-and-hold returns, $W_{i, t}=W_{0, t} \cdot \prod_{t=1}^{T}\left(1+r_{i, t}\right)$. Applied wealth relatives are market-to-equity offering $\left(W_{m, T} / W_{i, T}\right)$ and equity offering-to-market $\left(W_{i, T} / W_{m, T}\right)$, respectively. Two versions of the market model are applied, the standard method where the abnormal return (1) is $M A R_{i t}=r_{i t} C\left(\alpha+\beta \cdot r_{m t}\right)$, but also by subtracting the firm-specific return from the market return (2) $M A R_{i t}=\left(\alpha+\beta \cdot r_{m t}\right) C r_{i t}$. The $M A R_{i t}$ is used to calculate the transformed buy-and-hold abnormal return (T-BHAR). Standard deviations are shown in parentheses.

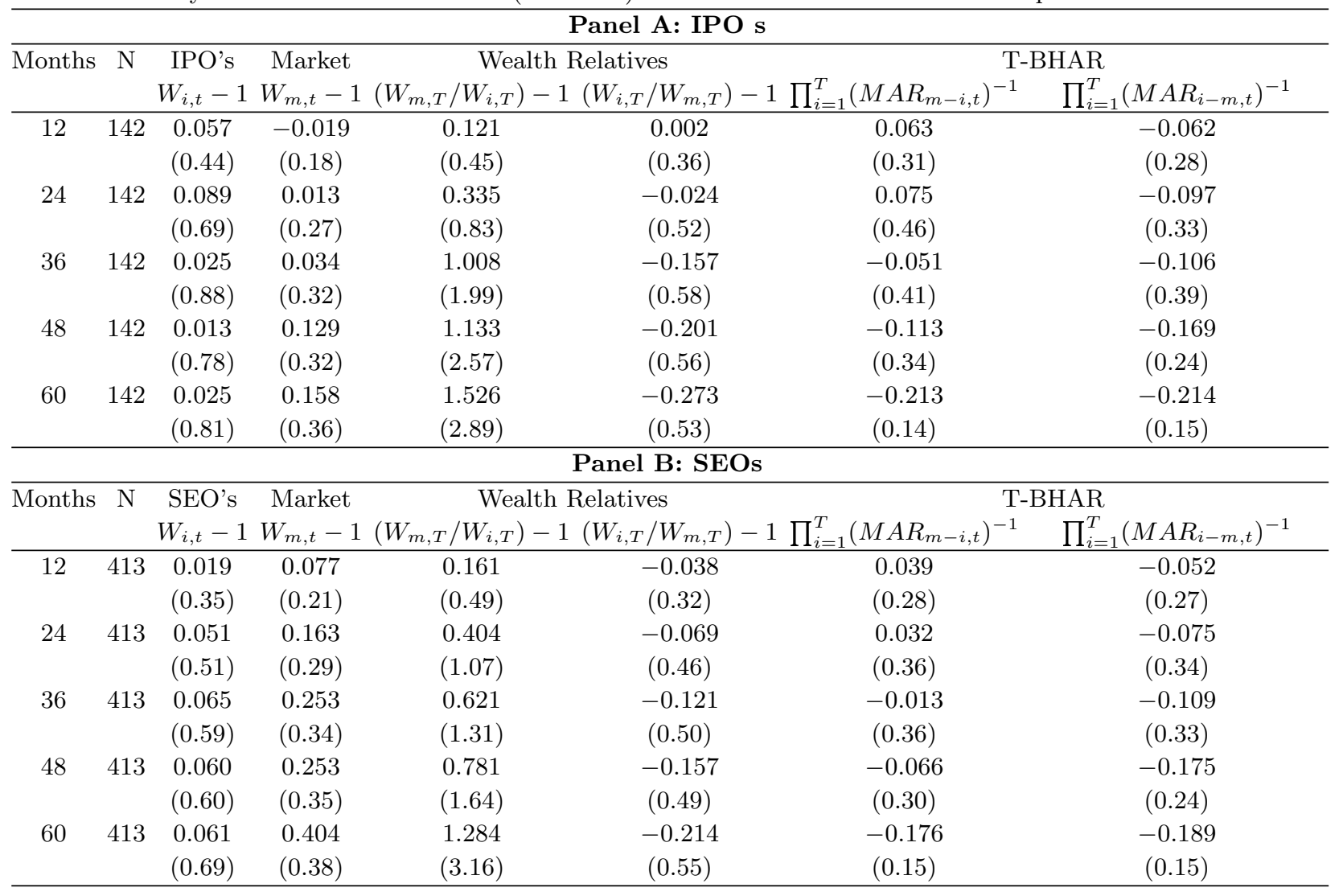


FIG. 1a. The Expected Mean and Volatility in IPOs

The development in expected mean and volatility are shown for the average buyand-hold return. The development in average buy-and-hold returns is shown in Panel $\mathrm{A}$ and $\mathrm{C}$ for wealth relative market-to-equity offering $\left(W_{m, T} / W_{i, T}\right)$ and equity offering-to-market $\left(W_{i, T} / W_{m, T}\right)$, respectively. In panels $\mathrm{B}$ and $\mathrm{D}$, the cross-sectional average buy-and-hold return are decomposed in a transformed mean component, $e^{\alpha_{T} \cdot T}-1$, and in a volatility component, $e^{1 / 2 \sigma_{T}^{2} \cdot T}-1$. The volatility component is independent of whether wealth relative $W_{m, T} / W_{i, T}$ ) and $\left(W_{i, T} / W_{m, T}\right)$ are used, and the volatility component has a positive influence on the average long-horizon wealth relative performance. The transformed mean component of the buy-and-hold return depends on the used transformation of wealth relatives.

Panel A Expected BHR of Wealth Relative IPO versus Market



Panel B Mean and volatility components IPO versus Market

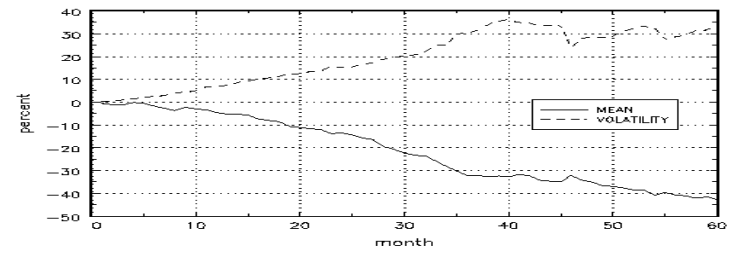

Panel C Expected BHR of Wealth Relative Market versus IPO

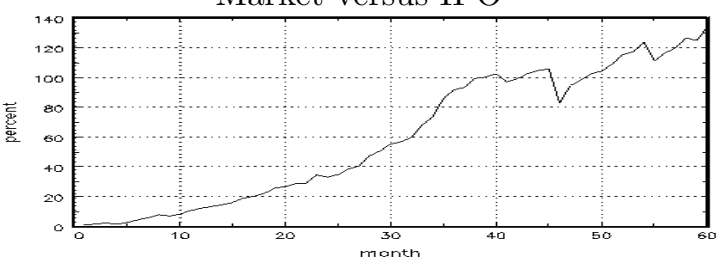

Panel D Mean and volatility components Market versus IPO

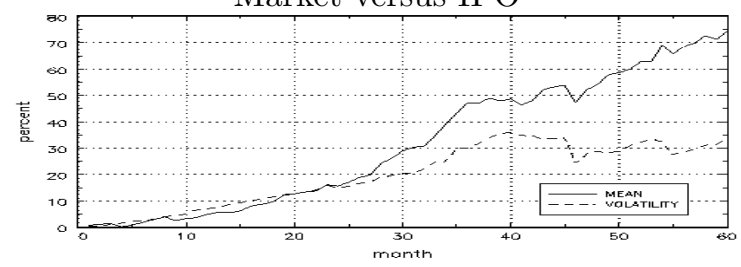


Figure 1 illustrates the difficulty of drawing inferences based only on expected buy-and-hold returns (panel A and panel C). A total of 10 percent of the IPO stocks' cross-sectional buy-and-hold returns are rejected as being log-normally distributed at a five percent level of significance, while 19 percent of the SEO stocks' cross-sectional buy-and-hold returns are rejected as being log-normally distributed at a five percent level of significance. ${ }^{15}$ Figure $1 \mathrm{~A}$ provides the expected cross-sectional buy-and-hold returns and the decomposition of the wealth relatives related to the IPO stocks. Panel $\mathrm{A}$ and panel B in Figure IA show the results of the IPO-to-market wealth relative. Panel A shows that the IPO stocks under perform relative to the market by 22.9 percent after five years. Using the volatility-adjusted performance measure (panel B), the IPO stocks under pe rform relative to the market by 43.7 percent after five years. Using the market-to-IPO wealth relative (panel C), the market out performs the IPO stocks by 142.9 percent. The difference between the results in Table 2 and Figure I arises from the transformation of the buy-and-hold returns into log-normality. The volatility- adjusted performance of the market-to-IPO wealth relative shows that the market out performs the IPO stocks by 77.5 percent after five years (Panel D). Comparing pa nel B and panel D confirms an identical volatility component for the IPO-to-market wealth relative and the marketto-IPO wealth relative.

Figure IB provides the expected cross-sectional buy-and-hold returns and the decomposition of the wealth relatives related to the SEO stocks. Panel A and panel B in Figure IB show the results of the SEO-to-market wealth relative. Panel A in Figure IB shows that the SEO stocks under perform relative to the market by 17.8 percent after five years. Panel B shows volatility-adjusted performance measure: the SEO stocks under perform by 38.1 percent after five years. Panel $\mathrm{C}$ in Figure IB shows the market-to-SEO wealth relative: the market index out performs SEO stocks by 114.4 percent after five years. Applying the volatility-adjusted performance measure, the market out performs the SEO stocks by 61.5 percent after five years.

A correct inference of the average buy-and-hold returns is to adjust for the volatility component in the reported returns. Doing so, we found that the average buy-and-hold returns tend to under-estimate the under performance of equity offerings. For example, for IPO stocks the volatilityadjusted under performance is 43.7 percent compared to the average under

\footnotetext{
${ }^{15}$ The test statistics are based on Door nik and Hansen (1994) that adjust for sample size. The problem is severe for the market model's estimates of buy-and-hold returns while the buy-and-hold returns of wealth relatives are acceptable log-normally distributed. Figures summarizing the probability level of normality and corresponding chisquared statistics for wealth relatives in the spirit of Loughran and Ritter (1995) are shown in appendix $\mathrm{C}$
} 
FIG. 1b. The Expected Mean and Volatility in SEOs.

The development in expected mean and volatility are shown for the average buyand-hold return. The development in average buy-and-hold returns is shown in Panel $\mathrm{A}$ and $\mathrm{C}$ for wealth relative market-to-equity offering $\left(W_{m, T} / W_{i, T}\right)$ and equity offering-to-market $\left(W_{i, T} / W_{m, T}\right)$, respectively. In panels $\mathrm{B}$ and $\mathrm{D}$, the cross-sectioal average buy-and-hold return are decomposed in a transformed mean component, $e^{\alpha_{T} \cdot T}-1$, and in a volatility component, $e^{1 / 2 \sigma_{T}^{2} \cdot T}-1$. The volatility component is independent of whether wealth relative $\left(W_{m, T} / W_{i, T}\right)$ and $\left(W_{i, T} / W_{m, T}\right)$ are used, and the volatility component has a positive influence on the average long-horizon wealth relative performance. The transformed mean component of the buy-and-hold return depends on the used transformation of wealth relatives.

Panel A Expected BHR of Wealth Relative

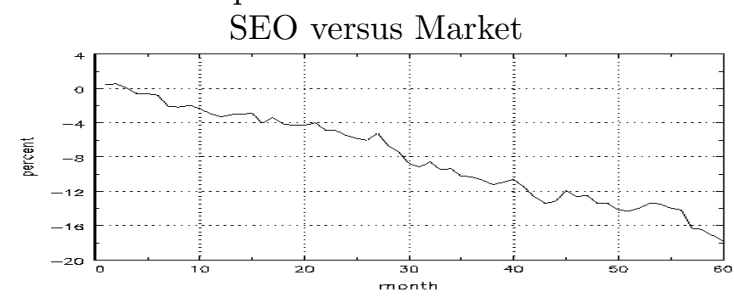

Panel B Mean and volatility components SEO versus Market

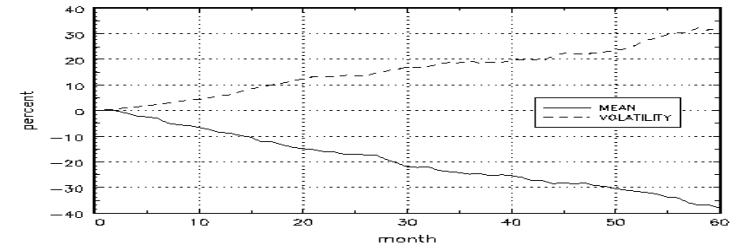

Panel C Expected BHR of Wealth Relative Market versus SEO

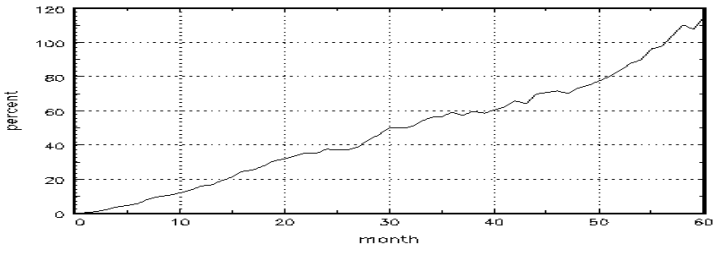

Panel D Mean and volatility components Market versus SEO

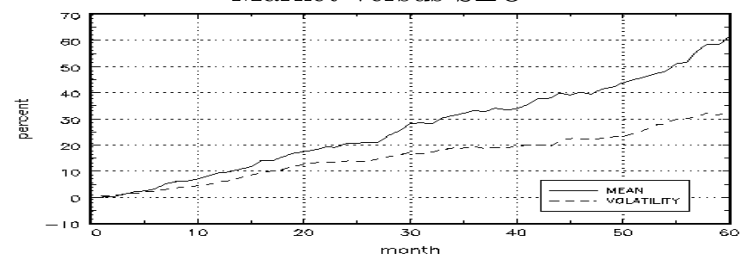


performance, as reported in Table 2, of 27.3 percent. Similarly, for SEO stocks the volatility-adjusted under performance is 38.1 percent compared to an average under performance of 21.4 percent. Overall, Figure I shows that the transformed mean component and the volatility component either amplify or weaken one another. Therefore, the volatility-adjusted performance depends on whether the transformed mean component is positive or negative.

\subsection{Test of the Mean and Volatility Component}

Figure II displays the test statistics graphically rather than nume rically. Panels $\mathrm{A}$ and $\mathrm{C}$ show the transformed mean components, and panels $\mathrm{B}$ and $\mathrm{D}$ show the volatility components. Tests of the market relative to IPO stocks and SEO stocks show that the transformed mean component of the expected cross-sectional buy-and -hold returns is significantly different from zero at a five percent level of significance after 15 months and after five months, respectively. Figure II also shows the marginal estimates for transformed mean components and volatility components and their respective 95percent marginal confidence intervals. Any number outside the confidence intervals is significant against the marginal estimates.

The volatility component always contributes positively to the expected cross-sectional buy-and-hold returns. If the transformed mean component is zero and the volatility is positive, and constant, then the average will increase with the time horizon. The reason is that the positive gains accumulate more than the losses, even if the transformed mean component is zero. This accounts for the observed right skewness in the development of the cross-sectional buy-and-hold returns. To illustrate the inference of long-run performance in figures I and II, consider the performance of the IPO stocks after 18 months. Figure IA illustrates that the expected crosssection buy-and-hold return of the wealth relative of IPO stocks relative to the market is zero. However, Figure IIA shows that the mean component is negative 10 percent and Figure IIB shows that the volatility component is positive 12.5 percent. Both components are statistically different from zero. The average over performance of the market is 26.5 percent based on the wealth relative of the ratio of the market relative to the IPO stocks in Figures IC and ID. This over performance consists of a significant mean component of 12.5 percent and a significant volatility component over performance of 12.5 percent. Thus, to consider an average cross-sectional buy-and-hold return does not by itself make any sense, whether it is negative 10 percent or positive 26.5 percent. However, the decomposition does make sense because the size of the volatility component is the same whether one looks at the IPOs to market $(\mathrm{S} / \mathrm{M})$ ratio or the market to IPOs $(\mathrm{M} / \mathrm{S})$ ratio. It makes sense to filter out the volatility component because it is independent of the wealth ratio, and to look only at the mean 
FIG. 2. Test of the Volatility-Adjusted Security Performance We test the maximum likelihood estimate $\alpha_{T} \cdot T$. The test is $H_{0}: \alpha_{T} \cdot T=0$, $H_{1}: \alpha_{T} \cdot T \neq 0$ where $T=\{1, \cdots, 60\}$. The maximum likelihood estimate $\alpha_{T} \cdot T$ is shown as 95 percent marginal confidence intervals. The transformed mean component $e^{\alpha_{T} \cdot T}-1$ for the wealth relative $\left(W_{i, T} / W_{m, T}\right)$ and its confidence intervals are shown in panel $\mathrm{A}$ and $\mathrm{C}$, respectively. The volatility component $e^{1 / 2 \sigma_{T}^{2} \cdot T}-1$ and its confidence intervals are shown in panel $\mathrm{B}$. The volatility component is the same whether the wealth relative $\left(W_{m, T} / W_{i, T}\right)$ or $\left(W_{i, T} / W_{m, T}\right)$ is used and therefore it can be considered with both panel A and $\mathrm{C}$.

Panel A Mean Component IPO versus Market

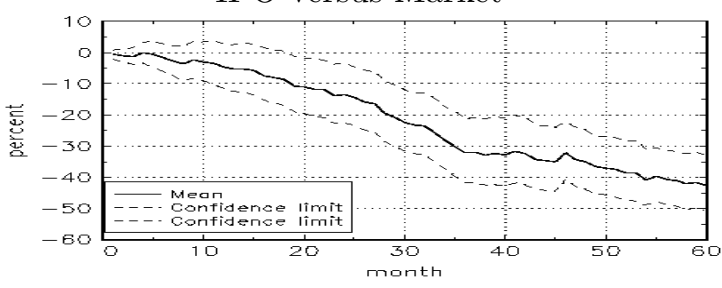

Panel B Volatility Component IPO versus Market

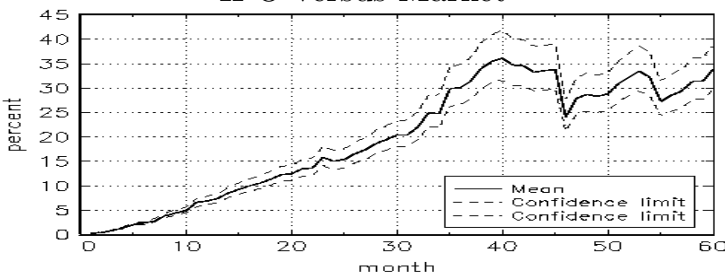

Panel C Mean Component SEO versus Market

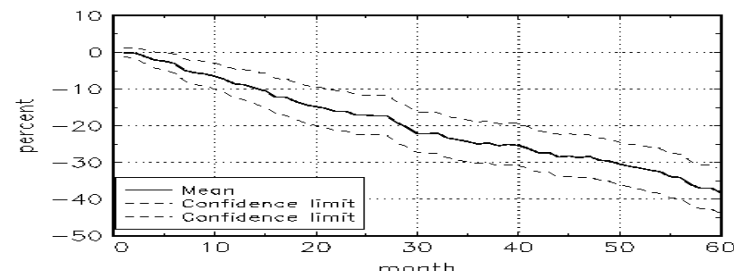

Panel D Volatility Component SEO versus Market

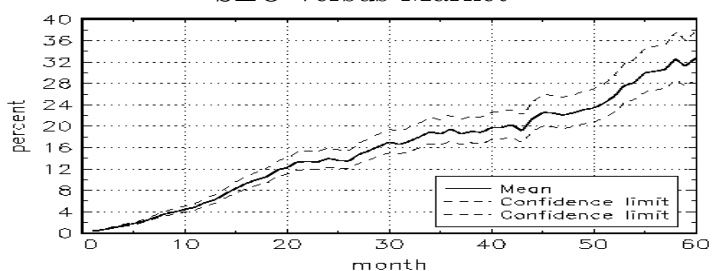


component before making any inference. Looking at the mean component we see that the IPO stocks under perform the market by 10 percent after 18 months. After 60 months the mean-component under performance of the IPO stocks is 43.7 percent, which is equivalent to a mean-component over performance of 77.5 percent. If the decomposition had not been made the cross-sectional expected buy-and-hold return would have been in the range between an underperformance of negative 22.9 percent and an over performance of 142.9 percent (see Table III). These numbers are not easily compared. After five years the volatility component for either ratio is 36.9 percent. To calculate the average cross sectional buy-and-hold return, we must multiply the gross mean component and volatility component. ${ }^{16}$

\subsection{Categorized into Hot Issue Period versus Cold Issue Pe- riod}

We partitioned the IPOs and SEOs into a hot (cold) issue period, and we investigated the IPO stocks for the hot issue period 1983-1986. IPO stocks on the Copenhagen Stock Exchange show a strong relationship between high initial returns and long-run performance: high initial returns experience negative long-run returns after 5 years. Table 3 presents the results of hot issues for the period 1983-1986 and the cold issues for the period $1987-1993 .^{17}$

\footnotetext{
${ }^{16}$ The average performance after five years with a mean component of negative 43.65 percent and a volatility component of 36.87 percent equals $(-0.4365+1) *(0.3687+1)-1$ or negative 22.87 percent in accordance with expression 8 .

${ }^{17}$ A similar hot issue period from 1983 -1986 is reported in Uhlir (1989) for the German IPO market.
} 





Besides showing sub-sample periods, Table 3 also displays the different methods of calculating long-run returns. All three methods show that the market outperforms equity offerings after five years for the hot issue period. Method one, which does not adjust for right-skewness, shows that the market out performs IPO stocks by 172.9 percent, while the volatilityadjusted buy-and-hold return shows the IPOs over performing by 99.9 percent (method 3). For the cold issue period, using method one, the market out performs IPO stocks by 64.6 percent after five years while the volatility- adjusted out performance is 29.3 percent after five years. These reported out performance percentages are numbers that arise when the market is measured relative to the equity issue stocks. However, for the reverse wealth-relative measure (IPO-to-market) using method one the under performance in the hot issue period is only 36.4 percent after five years and for the cold issues period the under performance is only 9.0 percent. This may seem odd but it is caused by the fact that the volatility component is identical for the two wealth-relative measures (IPO-to-market and marketto-IPO). Adjusting for the volatility, i.e. using method three, we find that hot (cold) issues period under perform by 50.0 percent (22.0 percent). The measures of volatility-adjusted performance are compatible irrespective of whether we measure out performance.

We also investigated whether or not this inverse relationship exists between the one year return and the five-year returns. Our results show that the under performance after one year for hot (cold) issue periods is 4.1 percent (5.9 percent) while the under performance after five years for hot (cold) issue periods is 50.0 percent (22.6 percent) using method three. Thus, the results may indicate that investors who invest in initial public offerings in cold issue periods are better off in the long run than those who invest in initial public offerings during a hot period.

All three methods in Table 3 show that the 142 IPO stocks and 413 SEO stocks under performed for the entire sample period. The volatilityadjusted performance measure shows that the IPO stocks and the SEO stocks significantly under performed the market by 43.7 percent and 38.1 percent. The results confirm the similarities between the long-run performance of IPO stocks and SEO stocks and that, relative to the market the IPO stocks under perform more than SEO stocks.

\section{CONCLUSION}

We started with Ritter's puzzle to which we respond: why do long-run returns of equity offerings persistently underperform? We suggested that a key to the puzzle is to measure long-run returns using WRs. Decomposing the relatives gives us an answer: we still see underperformance but we can explain it better. We showed WR provides a better interpreta- 
tion of long-run returns than just considering a simple arithmetic average buy-and-hold return. First, we identified transformations of data that exhibit log-normally distributed cross-sectional buy-and-hold returns. Second, we decomposed the expected cross-sectional buy-and-hold returns into transformed mean components and volatility components. For the wealth relative measure, we showed that it is necessary to correct the expected cross-sectional buy-and-hold return for the volatility component. We reported that whether accumulated returns are calculated using the marketto-security or the security-to-market wealth relative, the volatility component introduces an identical upward bias. The expected buy-and-hold returns must be adjusted for this volatility component to show coherent security performance. We investigated the long-run security performance of 142 IPOs and 413 SEOs from Denmark during the period 1983-1998. The volatility-adjusted buy-and-hold returns show that IPOs and SEOs under performed over a five-year period by 43.7 percent and 38.1 percent, respectively. The under performance is more evident for equity offerings in a hot issue period compared to a cold issue period.

\section{APPENDIX A}

\section{Transformed Buy-and-Hold Returns}

An alternative measure of long-run abnormal returns denoted by the transformed buy-and-hold return (T-BHAR) is:

$$
\mathrm{T}_{-\mathrm{BHAR}}-m, T=\prod_{t=1}^{T}\left(1+a r_{t}\right)
$$

where the abnormal return is defined as $a r_{t}=r_{i, t} C r_{m, t}$. The usual measurement of cross-sectional buy-and-hold return is defined $\mathrm{BHAR}_{i-m, T}=$ $\left(\prod_{t=1}^{T}\left(1+r_{i, t}\right)-\prod_{t=1}^{T}\left(1+r_{m, t}\right)\right)$. The average cross-sectional T-BHAR is:

$\overline{\mathrm{T}-\mathrm{BHAR}}_{i-m, T}=\frac{1}{N} \sum_{i=1}^{N}\left(\prod_{t=1}^{T}\left(1+a r_{t}^{i-m}\right)\right)=\frac{1}{N} \sum_{i=1}^{N}\left(e^{\sum_{i=1}^{T} \log \left(1+a r_{t}^{i-m}\right)}\right)$

Applying a geometric Brownian motion in continuous times:

$$
d \log \mathrm{T}-\mathrm{BHAR}=\mu_{a r} d t+\sigma_{a r} d z_{t}
$$

where

$$
\mathrm{T}_{-\mathrm{BHAR}}-m, T=e^{\mu_{a r} T+\sigma_{a r} z_{T}}
$$

where $z_{T} \sim N(0, T)$. A serious problem arises when applying (A.4) if the abnormal return $a r_{t}$ at any time is less than minus one because the loga- 
rithm in that case cannot be taken on $\left(1+a r_{t}\right)$. An explicit structure of the geometric Brownian motion can be enforced on the BHAR. But, BHAR consists of a difference between two exponential expressions. Therefore , it does not assist in separating the mean component from the volatility component. Empirically, the various combinations $\mathrm{T}_{-} \mathrm{BHAR}_{i-m, T}$ and $\mathrm{T}_{-\mathrm{BHAR}_{m-i, T}}$ are equivalent to the wealth relatives with the only difference being the sizes of the numbers.

\section{APPENDIX B}

\section{Decomposing Expected Buy-and-Hold Returns}

Define a wealth relative at time $T$ by the variable $W_{T}$. If the logarithm of the wealth relative at time $T$ is normally distributed with transformed mean $\alpha_{T} \cdot T$ and variance $\sigma_{T}^{2} \cdot T$ :

$$
\log \left(W_{T}\right) \sim N\left(\alpha_{T} \cdot T ; \sigma_{T}^{2} \cdot \sqrt{T}\right)
$$

then the wealth relative, $W_{T}$, is log-normally distributed: $W_{T}=e^{\log \left(W_{T}\right)}$. As $W_{T}$ is lognormally distributed the expected value of the wealth relative is given by:

$$
E\left(W_{T}\right)=e^{\mu_{T} \cdot T}=e^{\alpha_{T} \cdot T+\frac{1}{2} \sigma_{T}^{2} \cdot T}=\underbrace{e^{\alpha_{T} \cdot T}}_{\begin{array}{c}
\text { Transformed } \\
\text { meancomponent }
\end{array}} \cdot \underbrace{e^{\frac{1}{2} \sigma_{T}^{2} \cdot T}}_{\begin{array}{c}
\text { Volatility } \\
\text { component }
\end{array}}
$$

where the definition $\mu_{T} \equiv \alpha_{T}+\frac{1}{2} \sigma_{T}^{2}$ is used. The variance of $W_{T}$ is given by:

$$
\operatorname{Var}\left(W_{T}\right)=e^{\left(2 \mu_{T}+\sigma_{T}^{2}\right) \cdot T} \cdot\left(e^{\sigma_{T}^{2} \cdot T}-1\right)=e^{\left(2 \cdot\left(\sigma_{T}+\frac{1}{2} \sigma_{T}^{2}\right)+\sigma_{T}^{2}\right) \cdot T} \cdot\left(e^{\sigma_{T}^{2} \cdot T}-1\right)
$$

Using the structure of a geometric Brownian motion with the dynamics $d W_{t}=\mu_{t} W_{t} d t+\sigma_{t} W_{t} d Z_{t}$ and applying Ito's lemma on $\log \left(W_{T}\right)$ :

$$
\begin{aligned}
d \log \left(W_{t}\right) & =\frac{\partial \log \left(W_{t}\right)}{\partial t} d t+\frac{\partial \log \left(W_{t}\right)}{\partial W_{t}} d W_{t}+\frac{1}{2} \cdot \frac{\partial^{2} \log \left(W_{t}\right)}{\partial W_{t}^{2}}\left(d W_{t}\right)^{2} d t \\
& =\mu_{t} d t+\sigma_{t} Z_{t}-\frac{1}{2} \sigma_{t}^{2} d t \\
& =\left(\mu_{t}-\frac{1}{2} \sigma_{t}^{2}\right) d t+\sigma_{t} Z_{t}
\end{aligned}
$$

where $\frac{\partial \log \left(W_{T}\right)}{\partial t}=0, \frac{\partial \log \left(W_{T}\right)}{\partial W_{T}}=\frac{1}{W_{T}}, \frac{\partial^{2} \log \left(W_{T}\right)}{\partial W_{T}^{2}}=-\frac{1}{W_{T}^{2}}$ 
This provides the mean component and the volatility component:

$$
\begin{aligned}
& W_{T}=W_{0}+\int_{0}^{T} \mu_{t} W_{t} d t+\int_{0}^{T} \sigma_{t} W_{t} d Z_{t} \\
& W_{t}=e^{\left(\mu_{T}-\frac{1}{2} \sigma_{T}^{2}\right) \cdot T}+\sigma_{T} \cdot Z_{T}
\end{aligned}
$$

where $\mu_{T} \equiv \alpha_{T}+\frac{1}{2} \sigma_{T}^{2}$ is the drift and $\alpha_{T}$ and $\sigma_{T}^{2}$ are the marginal parameter estimates an any point in time. At time $T$ the transformed mean component and the volatility component of $\log \left(W_{T}\right)$ is $\alpha_{T} \cdot T$ and $\sigma_{T}^{2} \cdot \sqrt{T}$.

\section{APPENDIX C}

\section{Test Statistics for Normality}

The test statistics that adjusts for sample size are based on Doornik \& Hansen (1994). Panel A and B summarize the probability level of normality and corresponding chi-squared statistics for wealth relatives in the spirit of Ritter (1991) and Loughran \& Ritter (1995). The horizontal line shows the 5 percent level of significance for being log-normally distributed. 
Panel A: Chi-squared of normality for wealth relatives of IPO's

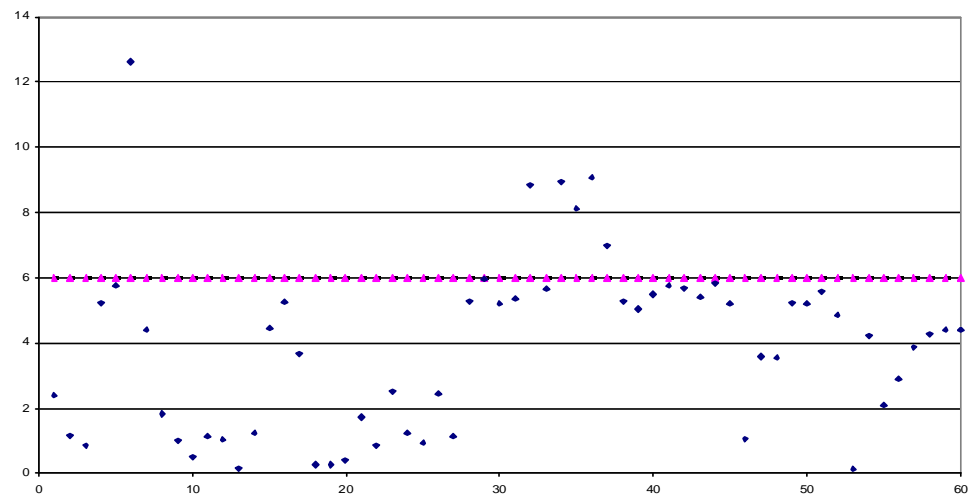

Panel B: Chi-squared of normality for wealth relatives of SEO's

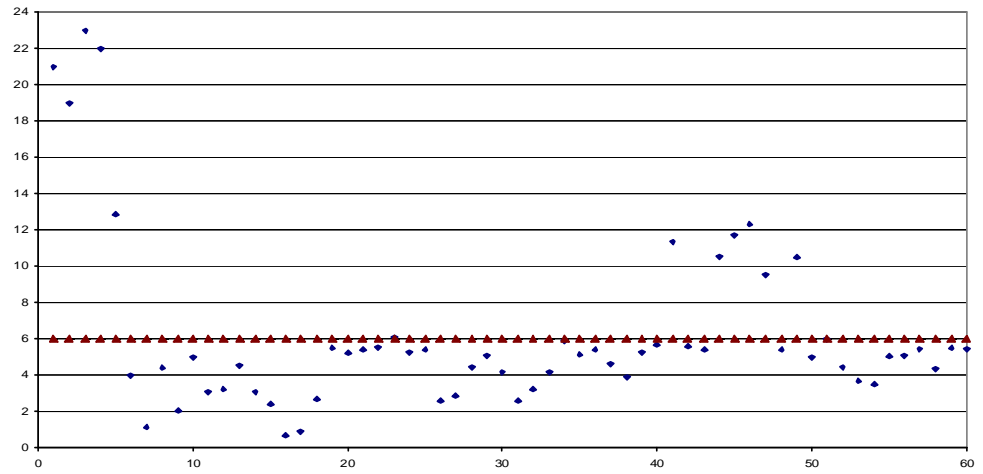

\section{REFERENCES}

Agrawal, A. et al., 1992. The post-merger performance of acquiring firms: A reexamination of an anomaly. Journal of Finance Vol. 47, 1605-1621.

Barber, B. M. and J. D. Lyon, 1997. Detecting long-run abnormal stock returns: The empirical power and specification of test statistics. Journal of Financial Economics Vol. 43, 341-372.

Barberis, N. et al., 1998. A model of investor sentiment. Journal of Financial Economics Vol. 49, 307-343.

Bigelli, M., 1997. The quasi-split effect, active insiders, and positive abnormal returns in European equity rights issues: Evidence from Italy, Unpublished working paper, University of Bologna.

Brav, A., 2000. Inference in long-horizon event studies: A Bayesian approach with application to initial public offerings. Journal of Finance Vol. 55, 1979-2016.

Bøhren, Ø. et al., 1997. Why underwrite rights offerings? Some new evidence. Journal of Financial Economics Vol. 46, 223-261. 
Canina, L. et al., 1998. Caveat compunder: A warning about using the daily CRSP equal-weighted index to compute long-run excess returns. Journal of Finance Vol. 53, 403-416.

Conrad, J. and G. Kaul, 1993. Long-term market overreaction or biases in computed returns. Journal of Finance Vol. 48, 39-63.

Cowan, A.R. and A.M.A. Sergeant, 1997. Interacting biases, non-normal return distributions and the performance of parametric and bootstrap tests for long-run event studies. Unpublished Working Paper, College of Business, Iowa State University.

Daniel, K. et al., 1998. A theory of overconfidence, self-attribution, and security market under- and over-reactions. Journal of Finance Vol. 53, 1839-1885.

Dhatt, M.S. et al., 1996. Seasoned equity issues: The Korean experience. Pacific-Basin Finance Journal Vol. 4, 31-43.

Doornik, J. A. and H. Hansen, 1994. An omnibus test for univariate and multivariate normality. Unpublished Working Paper. Nuffield College, Oxford University.

Dubois, M. and P. Jeanneret, 1998. The long-run performance of seasoned equity offerings with rights. Unpublished Working Paper. University of Neuchâtel.

Eckbo, B. E. and R.W. Masulis, 1995. Seasoned equity offerings: A survey in Jarrow et al. Finance Handbooks in Operations Research and Management Science. NorthHolland, Vol. 9, 1017-1072.

Fama, E. F., 1998. Market efficiency, long-run returns, and behavioral finance. Journal of Financial Economics Vol. 49, 283-306.

Hietala, P. and T. Löyttyniemi, 1991. Raising equity using rights issues: Evidence on signaling. Unpublished Working Paper. INSEAD, Fontainebleu, France

Ibbotson R.G. and J.F. Jaffe, 1975. Hot issues markets. Journal of Finance Vol. 30, 1027-1042.

Ibbotson R.G. and J.R. Ritter, 1995. Seasoned equity offerings: A survey in Jarrow et al. Finance Handbooks in Operations Research and Management Science. NorthHolland, Amsterdam, Vol. 9, 993-1016.

Ikenberry, D. et al., 1995. Does the stock market overreact? Journal of Finance Vol. 40, 793-805.

Jakobsen, J. and O. S.rensen, 2001. Decomposing and testing long-term returns: An application on Danish IPOs. European Financial Management Vol. 7, 393-417.

Kang, J. and R. Stulz, 1996. How different are Japanese corporate finance? An investigation of new security issues. Review of Financials Studies Vol. 9, 109-139.

Kelharju, M., 1993. The winner's curse, legal liability, and long-run price performance of initial public offerings in Finland. Journal of Financial Economics Vol. 18, 705723.

Kothari, S. P. and J. B. Warner, 1997. Measuring long-run security price performance. Journal of Financial Economics Vol. 43, 301-339.

Kunz, R.M. and R. Aggarwal, 1994. Why initial public offerings are under priced: Evidence from Switzerland. Journal of Banking and Finance Vol. 20, 1189-1210.

Lee, P. J. et al., 1996. Australian IPO pricing in the short and long run. Journal of Bank ing and Finance Vol. 20, 1189-1210.

Levis, M., 1993. The long-run performance of initial public offerings: The UK experience 1980-1988. Financial Management Vol. 22, 28-41.

Loderer, C.F. and H. Zimmermann, 1988. Stock offerings in a different setting: The Swiss case 1973-1983. Journal of Banking and Finance, 353-378. 
Loughran, T. and A. Vijh, 1997. Do long-run shareholders benefit from corporate takeovers? Journal of Finance Vol. 52, 176-1790.

Loughran, T. and J. R. Ritter, 1995. The new issues puzzle. Journal of Finance Vol. 50, 23-50.

Loughran, T., et al., 1994. Initial public offerings: International insights. Pacific-Basin Finance Journal Vol. 2, 165-199.

Lyon, J.D. et al., 1999. Improved methods for tests of long-run abnormal returns. Journal of Finance Vol. 54, 165-201.

Michaely, R. et al., 1995. Price reactions to dividend initiations and omissions. Journal of Finance Vol. 50, 573-608

Mitchell, M. and E. Stafford, 2000. Managerial decisions and long-term stock performance. Journal of Business Vol. 73, 287-320.

Page, M.J. and I. Reyneke, 1997. The timing and subsequent performance of initial public offerings on the Johannesburg stock exchange. Journal of Business Finance and Accounting Vol. 24, 1401-1420.

Ritter, J. R., 1991. The long-run performance of initial public offerings. Journal of Finance Vol. 46, 3-28.

Smith, C. W. Jr., 1986. Investment banking and the capital acquisition process. Journal of Financial Economics Vol. 15, 3-29.

Spiess, D. and J. Affleck-Graves, 1995. Underperformance in long-run stock returns follow ing seasoned equity offerings. Journal of Financial Economics Vol. 38, 243

Tsangarakis, N. V., 1996. Shareholder wealth effects of equity issues in emerging markets: Evidence from rights offerings in Greece. Financial Management Vol. 25, 21-32.

Uhlir, H., 1989. A reappraisal of the efficiency of financial markets in going public. In: The F.R.G., R. Guimaras et al (eds.), Springer-Verlag, Berlin. 